\title{
THE FUTURE OF BUSINESS IN SOCIAL ECONOMY OF THE WESTERN BALKAN COUNTRIES
}

\author{
Gentiana Gega \\ University "Haxhi Zeka” Peja, Kosovo \\ Ss. Cyril and Methodius University in Skopje \\ gentiana.gega@unhz.eu
}

\begin{abstract}
The most important innovation for Western Balkan countries is combining social, labor and economic development policies, together with sustainable development focus on increasing and sustaining the welfare and wellbeing of the people in this countries. The purposes of this study is to investigate current social economy in the Western Balkans countries (Albania, Kosovo, North Macedonia, Serbia, Montenegro and Bosnia and Herzegovina). To give an answer to the research question whether the socio-economic situation in Western Balkan countries is improving, we have firstly revise the literature to find out what different authors have found in recent researches concerning this area and the methods, models used in collecting, processing and analyzing data. The processing of the data of the above-mentioned has been done by the STATA software program, specifically using Linear Regression, Fixed Effect, Random Effect, Hausman Taylor Regression and Correlation \& Covariance. Based on the empirical results of this study, we conclude that the $R$ Square designation coefficient indicating a higher relationship between dependent variable (Social Development) and independent variables (economic growth, education, climate change, environment, health, poverty, social protection and labor). Economic growth, education, climate change, social protection and labor, environment, health and poverty force explain and have an impact on increase/decrease the social development of the Western Balkan countries during for the period 2009-2019. This research paper highlights an empirical analysis based on real data, statistical reports of the World Bank of the Western Balkan Countries. Given that these results are evident, economic situation in Western Balkan countries have to improve with establishing social economy exactly in key area for the rapid grow of this countries.
\end{abstract}

Keywords: Social economy, Business, Economic Growth.

JEL classification: $B 55, M 2, O 4$

\section{INTRODUCTION}

This paper is focused on the future of business in social economy of the Western Balkan Countries. The purposes of this study is to investigate current social economy in the Western Balkans countries (Albania, Kosovo, North Macedonia, Serbia, Montenegro and Bosnia and Herzegovina). Special emphasis in this paper is placed on the social economy in the countries of the Western Balkans. All Balkan countries face the same problems: insufficient growth, unemployment, low standard of living, lack of various social services, etc., so the Balkans also need social economy to reach its citizens, to identify their needs and to improve their wellbeing. This paper is important for all those who want to learn more about social economics especially in the contribution that that she brings to: contribution to achieving rapid growth, the contribution to better social services, the contribution to better governance, the contribution to exclusion social, contribution to the goal of employment, contribution to social inclusion and poverty alleviation, contribution to the goals of education, contribution to environmental goals, 
etc., the last four are also Europe's targets for 2020. The following factors will be investigated during this research: social development, economic growth, education, climate change, environment, health, poverty, social protection and labor.

Social Economy is both the agent and the instrument of inclusive and responsible growth in the UfM Region at varying degrees of progress that correspond to the heterogeneity of the EuroMediterranean region in terms of enabling environments and business cultures. The potential for job creation through Social Economy in the MENA Region and the Balkans remains to be largely unexplored in comparison to other regions, which presents an opportunity and poses question marks about the optimal path ahead in order to unleash the potential of a significant private sector player with more than 3.2 million enterprises and 15 million jobs (Social Economy Europe, 2019). The countries of the Western Balkans are currently facing unfavorable social situations, inadequate education, and poor health outcomes, including a number of micro efficiency issues in the context of low investment in the social sector (Matković, 2019). As far as the environment is concerned, the worst results of environmental performances among Western Balkan group are recorded in the case of Bosnia and Herzegovina. This country has seven indicators in the first priority level, one indicator in the second priority level, and no one indicator in the third priority level. In other words, it lags behind the Western Balkan group in even seven indicators, while exceeds the results of other countries in this group in only one indicator. That all Western Balkan countries and especially Bosnia and Herzegovina need to make a lot of efforts in a future development of its environmental performances (Radivojević et al., 2018).

Although a very popular topic in developed European countries and beyond, there is a lack of research for developing countries such as the Western Balkans. Due to the lack of research regarding this topic we have encountered many difficulties during the preparation of this paper. The results of this paper will contribute to the strengthening of knowledge, data and information in the field of social economy. Furthermore, this study provides additional evidence regarding the social economy in the Balkans. The results of this study are important for social economy enterprises and organizations as they help them to priority people and communities over profit, to have inclusive and democratic governance, to reinvest most profits to pursue sustainable development goals, to create quality jobs for all, the provision of socially innovative service, to engage in recycling, reuse and repair of goods, to use the democratic decision-making process and the priority of people and labor on capital in the distribution of income, to guarantee opportunities equal, with a special focus on marginalized communities and minorities (providing services and training as well as creating employment opportunities for migrants, the homeless, Roma, people with disabilities, etc.), improving the care system health (child care, assistance for the elderly and people with disabilities, and not only).

The results of this research will support the idea of fostering the social economy in developing countries as a better opportunity to achieve a sustainable welfare for its citizens since in these countries, citizens even in the twenty-first century due to unemployment and poverty are being forced to leave their homeland to ensure a better welfare for themselves and their family. Also this study is important for the integration of the economies of the candidate countries as there will be an of the possibility on for establishing and fostering the social economy in Western Balkan countries, as a better way for the convergence of the EU standard.

In addition, the results of the study will help future researchers in the field of socio-economics and economic growth.

\section{IMPORTANCE OF SOCIAL ECONOMY}

Socio economic investigation is very important after that the European Union, Western Balkan and the rest of the world are experiencing disruptive technological, social and economic 
changes. The emergence and progress of digitalization, blockchain and big data, or the global rise of inequalities and job insecurity, are trends quickly changing our world, bringing new opportunities but also new challenges, and urging us to debate about the future that we want to build collectively. Western Balkans needs to develop social economy to improve the well-being of its citizens and to be closer to the European Union. Europe needs the social economy to reach out to its citizens, detect their real needs and make them part of creating solutions to a number of challenges, such as unemployment or precarious work, social exclusion, discrimination and racism, climate change or the lack of social cohesion (Social Economy Europe, 2021). The common values of the social economy, such as the primacy of people and the social objective over capital, democratic and/or participatory governance, reinvestment of most of the benefits to ensure the long-term sustainability of the enterprise and the provision of services to their members and local communities, actively contribute to social cohesion and hence to an innovative, smart, sustainable and inclusive growth, in addition to the creation of quality employment in Europe (European Union, 2017).

Figure 1: Social Economy as a new model for the future of Western Balkan, Europe and the World.

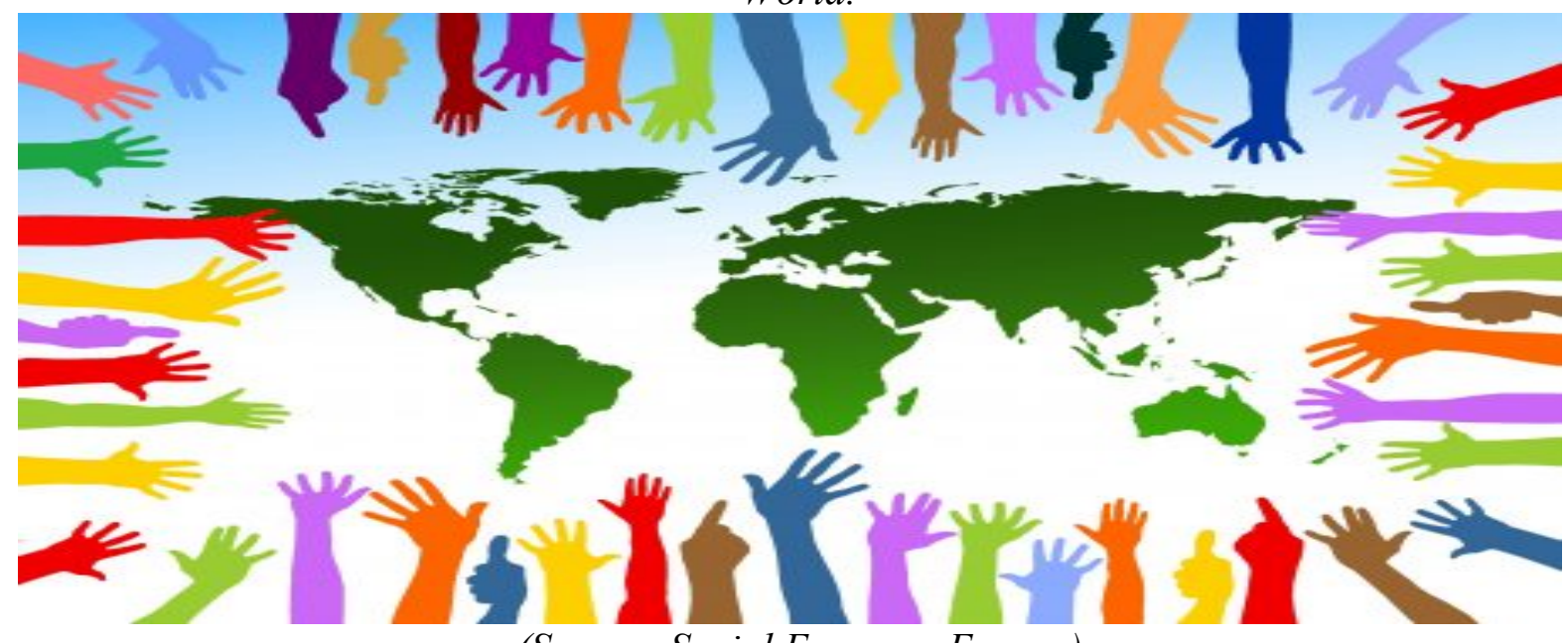

(Source: Social Economy Europe)

2.1. The opportunity that the social economy brings as an indicator that promotes the implementation of Agenda 2030 and 17 the implementation goals

"There are new opportunities for social economy to use platforms based on cooperative economy. We need to give social economy resources - not only technology but also skills", said Nicolas Schmit, Commissioner for Jobs and Social Rights. There are many opportunities to this issue. Most importantly is awareness of and legislation protection of the health of people from pollution and other harmful activities of business and other organizations (Adams, 2006). In North America, Europe and the rest of the developed world, there are strong checks and programs of legislation in place to ensure that people's health and wellness is strongly protected. It is also about maintaining access to basic resources without compromising the quality of life. The biggest hot topic for many people right now is sustainable housing and how we can better build the homes we live in from sustainable material. The final element is education encouraging people to participate in environmental sustainability and teaching them about the effects of environmental protection as well as warning of the dangers if we cannot achieve our goals.

The Sustainable Development Goals are a call for action by all countries - poor, rich and middle-income - to promote prosperity while protecting the planet. They recognize that ending poverty must go hand-in-hand with strategies that build economic growth and address a range 
of social needs including education, health, social protection, and job opportunities, while tackling climate change and environmental protection (United Nations, 2019). The 2030 Agenda for Sustainable Development, adopted by all United Nations Member States in 2015, provides a shared blueprint for peace and prosperity for people and the planet, now and into the future. At its heart are the 17 Sustainable Development Goals (1. No poverty, 2. Zero Hunger, 3. Good health and well-being, 4. Quality education, 5. Gender Equality, 6. Clean water and sanitation, 7. Affordable and clean energy, 8. Decent work and economic growth,

9. Industry, innovation and infrastructure, 10. Reduced inequalities, 11. Make cities and human settlements inclusive, safe, resilient and sustainable, 12. Responsible consumption and production, 13. Climate action, 14. Life below water, 15. Life on land, 16. Peace, justice and strong institutions, 17. Partnerships for the goals), which are an urgent call for action by all countries - developed and developing - in a global partnership. They recognize that ending poverty and other deprivations must go hand-in-hand with strategies that improve health and education, reduce inequality, and spur economic growth - all while tackling climate change and working to preserve our oceans and forests (United Nations, 2015).

The social economy emerges as an entrepreneurial and enterprise model for the future of Western Balkan, Europe and the World, a necessary alternative and a new opportunity for humanity. The social economy revolves around the values of primacy of people and the social objective over capital, democratic governance, solidarity and reinvestment of most of the profits/surplices to carry out sustainable development objectives (Gonzales, 2021).

\subsection{Description of indicators for all variables}

Social Development: Social development is the promotion of a sustainable society that is worthy of human dignity by empowering marginalized groups, women and men, to undertake their own development, to improve their social and economic position and to acquire their rightful place in society (Bilance, 1997). Social development is equality of social opportunities (Sen, 1995). Social development is the prioritization of human needs in a society.

Economic Growth: Economic growth is an increase in the production of economic goods and services, compared from one period of time to another. It can be measured in nominal or real (adjusted for inflation) terms. Traditionally, aggregate economic growth is measured in terms of gross national product (GNP) or gross domestic product (GDP), although alternative metrics are sometimes used. (Potters, 2021).

Education: Education is the process of facilitating learning, or the acquisition of knowledge, skills, values, morals, beliefs, and habits. Education is both the act of teaching knowledge to others and the act of receiving knowledge from someone else. Education also refers to the knowledge received through schooling or instruction and to the institution of teaching as a whole. Education has a few other senses as a noun. Education can be thought of as the transmission of the values and accumulated knowledge of a society. In this sense, it is equivalent to what social scientists term socialization or enculturation (Thomas, 2021).

Climate Change: Climate change refers to long-term shifts in temperatures and weather patterns. These shifts may be natural, such as through variations in the solar cycle. But since the $1800 \mathrm{~s}$, human activities have been the main driver of climate change, primarily due to burning fossil fuels like coal, oil and gas. Burning fossil fuels generates greenhouse gas emissions that act like a blanket wrapped around the Earth, trapping the sun's heat and raising temperatures. Examples of greenhouse gas emissions that are causing climate change include carbon dioxide and methane. These come from using gasoline for driving a car or coal for heating a building, for example. Clearing land and forests can also release carbon dioxide. Landfills for garbage are a major source of methane emissions. Energy, industry, transport, buildings, agriculture and land use are among the main emitters. (United Nations, 2021). 
Environment: The environment is the totality of all the external conditions affecting the life, development and survival of an organism (UN, 1997). Environment includes the living and nonliving things that an organism interacts with, or has an effect on it. Living elements that an organism interacts with are known as biotic elements: animals, plants, etc., abiotic elements are non-living things which include air, water, sunlight etc. (OECD, 2021).

Healthy: The WHO defines health as a state of "complete physical, mental and social wellbeing and not merely the absence of disease or infirmity." The Centers for Disease Control and Prevention, along with a range of WHO partners, endorses this definition. Being healthy, in their view, excludes having any disease (WHO, 2019)

Poverty: Poverty is a state or condition in which a person or community lacks the financial resources and essentials for a minimum standard of living. Poverty means that the income level from employment is so low that basic human needs can't be met (James Chen, 2020).

Social Protection \& Labor: Social protection \& Labor help individuals and families, especially the poor and vulnerable, cope with crises and shocks, find jobs, improve productivity, invest in the health and education of their children, and protect the aging population. Social protection systems that are well-designed and implemented can powerfully shape countries, enhance human capital and productivity, reduce inequalities, build resilience and end intergenerational cycle of poverty (World Bank, 2021).

\section{RESEARCH METHODOLOGY}

For the realization of this paper is studied, researched and reflected mainly domestic and foreign literature, publications and data from public institutions and international organizations. The methodology used in the paper will be a combination of qualitative and quantitative method, using different socio-economic data for Western Balkan countries, as for countries of the European Union. The methods used in this paper are: Theoretical review method; Statistical Method (Qualitative and Quantitative); Comparative Method and Analysis of Collected Data. To realize this research, the methodology consists in collection secondary data. The paper has been prepared using the analysis of secondary data, which are collected from the World Bank, and the variables being used include period of time 2009-2019. As far as the econometric model is concerned, the main methods used for analysis are: Descriptive analysis, Correlation \& Covariance, Linear Regression Random - Effects GLS Regression, Fixed - Effects Regression, Hausman - Taylor Regression, which are calculated through the STATA program. The main variables that are used are: social development (as a dependent variable) and economic growth, education, climate change, environment, health, poverty, social protection \& labor (as independent variable).

\section{EMPIRICAL ANALYSIS OF THE HYPOTHESIS AND STUDY FINDINGS}

In this chapter we will present all the results of the research which have been carried out for the verification and the hypothesis presented. The purposes of this study is to investigate current social economy in the Western Balkans countries (Albania, Kosovo, North Macedonia, Montenegro and Bosnia and Herzegovina).

\subsection{Econometric evaluation and hypothesis testing}

The hypothesis of this study is:

Wakened social-economic situation in Western Balkan countries have to improve with establishing social economy exactly in key area for the rapid grow of this countries.

For the verification of this hypothesis is apply quantitative method, based on the secondary data of the World Bank reports for the period 2009-2019. The data in these econometric models are 
data reported on an annual basis. The data are processed in the STATA program and for the verification of this hypothesis we have applied the following statistical tests: linear regression, fixed effect model and random effect and Hausman-Taylor regression. The variables used are: dependent variable (Social Development) and independent variables (economic growth, education, climate change, environment, health, poverty, social protection and labor). The reason for choosing the variables is as these are the main indicators of the social economy.

\subsubsection{Correlation analysis for the econometric model}

In table 3 shows the values of the correlation coefficient between SD and other independent variables: EG, ED, CCH, EN, HE, POV, SPL.

Table 1. Correlation analysis

\begin{tabular}{|l|l|l|l|l|l|l|l|l|}
\hline Variables & SD & EG & ED & CCH & EN & HE & POV & SPL \\
\hline SD & 1.0000 & 1.0000 & & & & & & \\
\hline EG & 0.6750 & -0.5753 & & & & & & \\
\hline ED & -0.7836 & -0.5063 & 1.0000 & & & & & \\
\hline CCH & -0.6762 & 0.6408 & 0.2951 & 1.0000 & & & & \\
\hline EN & 0.8205 & -0.2014 & -0.8884 & -0.2058 & 1.0000 & & & \\
\hline HE & -0.3371 & 0.0166 & 0.7192 & -0.4028 & -0.7683 & 1.0000 & & \\
\hline POV & 0.3618 & 0.6795 & -0.6640 & 0.3304 & 0.7188 & -0.8939 & 1.0000 & \\
\hline SPL & 0.9037 & 1.0000 & -0.5574 & -0.7761 & 0.5760 & -0.0325 & 0.0714 & 1.0000 \\
\hline
\end{tabular}

(Source: Author calculations in the STATA program)

In this table is presented the correlation with shows the level of correlation between dependent variable and independent variables. Based on the correlation results, the highest positive correlation has been shown by economic growth with (0.67), environment with (0.82), and social protection \& labor with $(0.90)$, education has shown negative correlation with $(-0.78)$ healthy $(-0.33)$ and climate change $(-0.67)$ on social development. Based on this result, we can see that this econometric made is statistically stable as the value of the error term is at a low level and does not impair the overall accuracy of this model. While the correlation to poverty (0.36), it is not negative but are found in the interval $0.00-0.49$, we can conclude that the term error is high.

\subsubsection{Linear regression analysis}

Table 2. Results of linear regression analysis

\begin{tabular}{|l|r|r|r|r|r|r|}
\hline SD & \multicolumn{1}{|l|}{ Coef. } & Std. Error & $\mathrm{t}$ & $\mathrm{P}>\mathrm{t}$ & $\begin{array}{l}\text { 95\% Conf. } \\
\text { Interval }\end{array}$ & \multicolumn{1}{l|}{$\begin{array}{l}\text { 95\% Conf. } \\
\text { Interval }\end{array}$} \\
\hline EG & -0.1672722 & 0.0882021 & -1.90 & 0.100 & -0.3758371 & 0.0412926 \\
\hline ED & -0.0266025 & 0.0986201 & -0.27 & 0.795 & -0.2598019 & 0.2065968 \\
\hline CCH & -0.0505532 & 0.0448818 & -1.13 & 0.297 & -0.1566819 & 0.0555755 \\
\hline EN & 0.4602378 & 0.1678484 & 2.74 & 0.029 & 0.0633393 & 0.8571363 \\
\hline HE & -0.0280574 & 0.7761842 & -0.04 & 0.972 & -1.863441 & 1.807327 \\
\hline POV & -0.154729 & 0.1770602 & -0.87 & 0.411 & -.5734099 & 0.2639519 \\
\hline SPL & 0.8685869 & 0.1947685 & 4.46 & 0.003 & .4080327 & 1.329141 \\
\hline cons. & 8.555298 & 56.78918 & 0.15 & 0.885 & -125.7298 & 142.8404 \\
\hline
\end{tabular}

(Source: Author calculations in the STATA program) 
According to the results in Table 2, we can see that all variables are within the $90 \%-95 \%$ confidence interval, except for the variables (education and health). The value of the parameter $\beta_{0}$ is at the standard level of significance ( $\mathrm{p}$-value $=0.000<0.05$ ).

The coefficient of determination ( $\mathrm{R}$ Square) in this case is $96 \%$ which shows a very high relationship between the dependent variable and the independent variables. This coefficient shows that for the value $96 \%$, economic growth, education, climate change, environment, health, poverty, social protection and labor in Western Balkan Countries for the period 20092019. If the other factors remain constant then the SD value will be 8.55.

However, if we assume that we have an in Economic growth of 1\% while keeping the other factors constant, this will affect the reduction of SD for $0.16 \%$. If we increase poverty by $1 \%$, keeping the other variables constant, then this will reduce SD by $0.15 \%$. If we have climate change growth of $1 \%$, keeping the other variables constant, then this will reduce SD by $0.05 \%$. These assertions are correct even at the level of $95 \%$ reliability ( $p$-value $=0.000<0.05$ ). If we increase the environment by $1 \%$, keeping the other variables constant, then this will reduce SD by $0.46 \%$. If we have an increase of social protection and labor by $1 \%$, keeping the other variables constant, then this will affect the increase of SD by $0.86 \%$. These assertions are correct even at the level of $95 \%$ reliability ( $p$-value $=0.000<0.05$ ).

It is worth noting that according to regression analysis, the greatest effects on social development are of environment and social protection \& labor. The main effects on social development is social protection \& labor, positive impact can come as a result of the work of non-governmental organizations which in recent years are working hard to reduce poverty and vulnerability by promoting efficient labor markets, reducing people's exposure to risk and increasing capacity to manage economic and social risks, such as unemployment, exclusion, disease, disability and old age.

\subsubsection{Random - Effects GLS Regression}

The specification of the dynamic panel model (Random-Effects) to test the impact of social development on the economic growth, education, climate change, environment, healthy, poverty and social protection \& labor is as follows:

$$
\begin{gathered}
\operatorname{LnSD}_{i t=} \beta_{0}+\beta_{1} \operatorname{LnEG} G_{i t}+\beta_{2} L n E D_{i t}+\beta_{3} L n C C H_{i t}+\beta_{4} L_{n E N_{i t}}+\beta_{5} L n H E_{i t}+\beta_{6} L_{n P O V} \\
+\beta_{7} L n S P L_{i t}+y_{i t}
\end{gathered}
$$

Given that all the symbols presented in the above econometric model are the same as in the regression analysis, except for the symbol i, which represents the code, through which the data were coded on an annual basis divided into 11 groups and the symbol $t$, representing the period 2009-2019, included in this empirical analysis. In table 3 will present the results of the regression analysis using the random effect.

Table 3. Model results Random - Effect GLS Regression

\begin{tabular}{|l|r|r|r|r|r|r|}
\hline SD & \multicolumn{1}{|l|}{ Coef. } & Std. Error & \multicolumn{1}{l|}{ Z } & \multicolumn{1}{l|}{ P $>\mathrm{Z}$} & $\begin{array}{l}\text { 95\% Conf. } \\
\text { Interval }\end{array}$ & \multicolumn{1}{l|}{$\begin{array}{l}\text { 95\% Conf. } \\
\text { Interval }\end{array}$} \\
\hline EG & -0.1672722 & 0.0882021 & -1.90 & 0.058 & -0.3401452 & 0.0056008 \\
\hline ED & -0.0266025 & 0.0986201 & -0.27 & 0.787 & -0.2198943 & 0.1666892 \\
\hline CCH & -0.0505532 & 0.0448818 & -1.13 & 0.260 & -0.13852 & 0.0374136 \\
\hline EN & 0.4602378 & 0.1678484 & 2.74 & 0.006 & 0.1312609 & 0.7892147 \\
\hline HE & -0.0280574 & 0.7761842 & -0.04 & 0.971 & -1.54935 & 1.493236 \\
\hline POV & -0.154729 & 0.1770602 & -0.87 & 0.382 & -0.5017607 & 0.1923026 \\
\hline SPL & 0.8685869 & 0.1947685 & 4.46 & 0.000 & 0.4868477 & 1.250326 \\
\hline cons. & 8.555298 & $56.78918 \mathrm{~d}$ & 0.15 & 0.880 & -102.7495 & 119.86 \\
\hline
\end{tabular}

(Source: Author calculations in the STATA program) 
Based on the values presented in the random effect results, the econometric model equation takes the following form: $L n S D_{i t}=8.555298+0.1672722_{i t}+0.0266025 i t+$ $0.0505532_{i t}+0.4602378 i t+0.0280574 i t+0.154729 i t+0.8685869 i t+0.11$

According to the results in Table 3, we can see that all variables are within the $90 \%-95 \%$ confidence interval, except for the variable (health with 0.02 ). The value of the parameter $\beta_{0}$ is at the standard level of significance ( $\mathrm{p}$-value $=0.000<0.05)$.

The value of the definition coefficient is $74 \%$, which means that for this value the independent variables explain the dependent variable (SD). Assuming that other factors affecting the social economy are constant, then the value of SD will be 8.55 . If we have economic growth of $1 \%$ while keeping the other variables constant, this will increase SD by $0.16 \%$ given that this is acceptable as it is within the $95 \%$ confidence interval.

If we have economic growth of $1 \%$, keeping the other variables constant, this will reduce SD by 0.16 . If education increases by $1 \%$, keeping the other variables constant, this will reduce SD by $0.02 \%$. If climate change increases by $1 \%$, keeping the other variables constant, this will reduce SD by $0.05 \%$. If the Environment grows by $1 \%$, keeping the other variables constant, this will increase SD by $0.46 \%$. If poverty increases by $1 \%$, keeping economic growth, education, climate change, environment, health, social protection and labor constant, this will reduce SD by $0.15 \%$. If Social protection \& labor increases by $1 \%$, keeping the other variables constant, this will increase SD by $0.86 \%$. The results of this model support the hypothesis validation.

\subsubsection{Fixed - Effects Regression}

One of the most important tests that has a very wide application in statistics for dynamic panel data is the fixed effects model. The main purpose of using this model is because the data are not relevant and in this analysis the fixed effects estimator is used referring to the internal regression coefficient estimator. The following table presents the results of the econometric model through fixed effects:

Table 4. Model results Fixed-Effect Regression

\begin{tabular}{|l|r|r|r|r|r|r|}
\hline SD & \multicolumn{1}{|l|}{ Coef. } & \multicolumn{1}{l|}{ Std. Error } & \multicolumn{1}{l|}{ Z } & \multicolumn{1}{l|}{$\begin{array}{l}\text { 95\% } \\
\text { Interval }\end{array}$} & $\begin{array}{l}\text { 95\% Conf. } \\
\text { Interval }\end{array}$ \\
\hline EG & -0.005961 & 0.0777631 & -0.08 & 0.942 & -0.2058573 & 0.1939354 \\
\hline ED & 0.1661107 & 0.088379 & 1.88 & 0.119 & -0.0610747 & 0.3932961 \\
\hline CCH & 0.1475101 & 0.0649014 & 2.27 & 0.072 & -0.0193242 & 0.3143444 \\
\hline EN & -0.8698557 & 2.521948 & -0.34 & 0.744 & -7.35273 & 5.613019 \\
\hline HE & -1.332557 & 0.6328631 & -2.11 & 0.089 & -2.959383 & 0.2942696 \\
\hline POV & 0.1074323 & 0.1367023 & 0.79 & 0.468 & -0.243972 & 0.4588367 \\
\hline SPL & 0.8497147 & 0.1272147 & 6.68 & 0.001 & 0.5226989 & 1.17673 \\
\hline cons. & 129.7071 & 94.42844 & 1.37 & 0.228 & -113.0289 & 372.4431 \\
\hline
\end{tabular}

(Source: Author calculations in the STATA program)

All independent variables are significate at the level of $95 \%$ reliability and all parameters are statistically measurable, except for the variable (economic growth with 0.005 ). The value of the parameter $\beta_{0}$ is at the standard level of significance $(\mathrm{p}$-value $=0.000<0.05)$.

The results of this model are in favor of interpreting the hypothesis, resulting in a positive relationship between education, climate change, poverty and social protection \& labor in Wester Balkan Countries. If education increases by $1 \%$, keeping to other factors, this will have the 
effect of increasing SD by $0.16 \%$. The standard error value for the parameter $\beta_{2}$ is 0.08379 , which means that this parameter has no standard error value and this comes as a result of positive correlation with SD. Estimator variation of parameter is $\beta_{2}=0.08379^{2}=0.08379$.

If Climate change increases by $1 \%$ keeping the other variables constant, this will have the effect of increasing the value of SD by $0.14 \%$. The standard error value for the parameter $\beta_{3}$ is 0.07776 which means that this parameter has no standard error value and this comes as a result of positive correlation with SD. Estimation variation of the parameter $\beta_{3}=0.07776^{2}=0.00604$ and this parameter has statistical significance because the actual value of the Test $\left(t_{f}=2.27\right)$ is a value greater than the critical value of this model $\left(t_{k r}=1.984\right)$.

Environment negatively affects the growth of the social economy, where $1 \%$ increase in the environment causes a decrease of SD by $1.33 \%$. The value of the standard error for the parameter $\beta_{4}$ is 2.5219 which is a value much larger than the standard error of the other parameters included in this econometric model. Estimation variation of the parameter $\beta_{4}=2.5219^{2}=6.35997$. Healthy negatively affects the growth of the social economy, where $1 \%$ increase in healthy causes a decrease of SD by $0.86 \%$. . The standard error value for the parameter $\beta_{5}$ is 0.6328 which means that this parameter has no standard error value and this comes as a result of positive correlation with SD. Estimation variation of the parameter $\beta_{5}=0.6328^{2}=0.40043$. If poverty increases by $1 \%$ keeping economic growth, education, environment, climate change, healthy and social protection \& labor constant this will have the effect of increasing the value of SD by $0.10 \%$. The value of the standard error for the parameter $\beta_{6}$ is 0.1367 which means that this parameter has no standard error value and this comes as a result of positive correlation with SD. Estimation variation of the parameter $\beta_{6}=0.1367^{2}=0.0186$.

The results of regression through the method of fixed effects turn out to be very important in the relationship between social protection \& labor and social development for the period 20092019. If social protection \& labor increases by $1 \%$ keeping constant economic growth, education, environment, climate change, healthy and powerful this will have the effect of increasing the value of SD by $0.84 \%$. The standard error value for the parameter $\beta_{7}$ is 0.1272 which means that this parameter has no standard error value and this comes as a result of positive correlation with SD. Estimation variation of the parameter $\beta_{7}=0.1272^{2}=0.0161$ and this parameter has statistical significance because the actual value of the $\mathrm{T}$ test $\left(t_{f}=6.68\right)$ is a value greater than the critical value of this model $\left(t_{k r}=1.984\right)$. It is worth noting that against independent variables, social protection \& labor has the greatest impact on the growth of the social economy. All this as a result of improving the well-being of citizens, helping individuals and families, especially the poor, better education for children, as a priority can be taken the young age of the population.

\subsubsection{Hausman - Taylor Regression}

Statistical data will also be tested through this model, in order to make comparisons with other statistical tests.

Table 5. Model results Hausman - Taylor Regression

\begin{tabular}{|l|r|r|r|r|r|r|}
\hline SD & \multicolumn{1}{|l|}{ Coef. } & \multicolumn{1}{|l|}{ Std. Error } & Z & P $>\mathrm{z}$ & \multicolumn{1}{l|}{$\begin{array}{l}\text { 95\% Conf. } \\
\text { Interval }\end{array}$} & $\begin{array}{l}\text { 95\% Conf. } \\
\text { Interval }\end{array}$ \\
\hline EG & -0.0297322 & 0.0709523 & -0.42 & 0.675 & -0.168796 & 0.1093317 \\
\hline ED & 0.1686635 & 0.0863121 & 1.95 & 0.051 & -0.0005052 & 0.3378321 \\
\hline CCH & 0.1410035 & 0.0629813 & 2.24 & 0.025 & 0.0175625 & 0.2644446 \\
\hline EN & 0.5570069 & 1.845848 & 0.30 & 0.763 & -3.060788 & 4.174802 \\
\hline HE & -1.307093 & 0.6177296 & -2.12 & 0.034 & -2.517821 & -0.0963652 \\
\hline
\end{tabular}




\begin{tabular}{|c|r|r|r|r|r|r|}
\hline POV & 0.093898 & 0.1326808 & 0.71 & 0.479 & -0.1661517 & 0.3539476 \\
\hline SPL & 0.8630772 & 0.1233667 & 7.00 & 0.000 & 0.6212829 & 1.104871 \\
\hline cons. & 84.707 & 60.26144 & 1.41 & 0.160 & -33.40326 & 202.8173 \\
\hline
\end{tabular}

(Source: Author calculations in the STATA program)

According to the results in Table 5, we can see that all variables are within the $90 \%-95 \%$ confidence interval, except for the variable (economic growth with 0.02$)$. The value of the parameter $\beta_{0}$ is at the standard level of significance ( $\mathrm{p}$-value $=0.000<0.05$ ).

Education positively affects a social economy. According to the data presented in the table above we can see that when education increases by $1 \%$ keeping the other variables constant, the effect will be in increase SD by 0.16. The standard error value for the parameter $\beta_{2}=$ 0.0863 , while the estimator variation for the parameter $\beta_{2}=0.0863^{2}=0.0863$. The actual value of the $\mathrm{T}$ test for this parameter is 1.95 which is approximately the same as the critical value of the $\mathrm{T}$ test (1.984).

Also Climate Change has a positive effect on the growth of the social economy. Assuming an increase of $1 \%$ in this index, affects the increase of SD by 0.14 . The standard error value for the parameter $\beta_{3}=0.0629$, while the estimator variation for the parameter $\beta_{3}=$ $0.0629^{2}=0.00395$. The actual value of the $\mathrm{T}$ test for this parameter is 2.24 which is a value greater than the critical value of the T test (1.984).

When the Environment grows by $1 \%$ keeping the other variables constant, the effect will be to increase the SD by $0.55 \%$. The standard error value for the parameter $\beta_{4}=1.8458$, while the estimator variation for the parameter $\beta_{4}=1.8458^{2}=3.4069$. The actual value of the $\mathrm{T}$ test for this parameter is 0.30 which is a value less than the critical value of the T test (1.984).

When healthy grows by $1 \%$ while keeping the other variables constant, the effect will be to reduce SD by 1.30 . Standard error for parameter $\beta \_5=0.6177$. The estimator variation of the parameter $\beta_{5}=0.6177^{2}=0.3815$ and the actual value is -2.12 .

Poverty positively affects the growth of the social economy. Assuming a $1 \%$ increase in this index, it affects the increase of SD by 0.09 . The standard error value for the parameter $\beta_{6}=$ 0.1326 , while the estimator variation for the parameter $\beta_{6}=0.1326^{2}=0.1758$. The actual value of the $\mathrm{T}$ test for this parameter is 0.71 which is a value less than the critical value of the $\mathrm{T}$ test (1.984).

The results of the Hausman-Taylor Regression model on the impact of social protection \& labor on the growth of the social economy are the same as the previous models. When social protection \& labor increases by $1 \%$ keeping constant economic growth, education, climate change, environment, healthy and poverty, the effect will be to increase SD by $0.86 \%$. The standard error value for the parameter $\beta_{7}=0.1233$, while the estimator variation for the parameter $\beta_{7}=0.1233^{2}=0.152$. The actual value of the T test for this parameter is 7.00 which is a value much higher than the critical value of the T test (1.984).

\section{CONCLUSION}

In this research we investigated the social economy in the Western Balkans Countries (Albania, Kosovo, North Macedonia, Serbia, Montenegro and Bosnia and Herzegovina). Social economy has to do with the economic factors of society. Some of the social-economic factors include: employment, education, and income. These factors relate to and influence one another. For example, our education will affect our employment, while employment will affect our income. The primary focus of this study is to present regional, national, and international perspectives on the production of data about the social economy. Considering that economics and social behavior, as two main pillars of the welfare of society, have an interrelationship between them, as well as given the fact that socioeconomics is the social science that studies how economic 
activity affects and how it is shaped by social processes. In general, it analyzes how modern societies progress, stagnate, or regress because of their local, regional economy, or the global economy.

Western Balkans Countries should be more far-sighted, follow in the footsteps of developed European countries, pay more attention to investing in the social economy. The countries of the Western Balkans, in addition to the criteria they must meet for EU membership, must focus more on the social economy, especially on improving the well-being of their citizens. It is known that the future of the state depends to a large extent on the youth, fortunately these countries have a young population, but day by day they are forced to leave their homeland in order to secure a better life for themselves and their family. Statistics show that many cities, especially rural areas, are being abandoned by young people. The countries of the Western Balkans need to think, engage and invest more in this issue as one day it will be too late.

As for the countries of the Western Balkans, countries that aspire to membership in the European Union, this sector is not so well known or better to say these countries are not making enough efforts in terms of recognition / development of social economy in the countries of their although recently it has been said that the social economy can contribute to achieving Europe 2020 goals (such as contributions to the employment, contributions to the social inclusion and poverty, contributions to the education and contributions to the environmental).

The data in this research are presented on an annual basis and are collected from the annual report of the World Bank. Based on the empirical analysis through econometric models, the results have shown that there are important relationships between the study variables and it turns out that this empirical analysis is possible. Based on the empirical results through econometric models we can conclude that according to the econometric model Linear regression analysis and Random - Effects GLS Regression, economic growth, education, climate change, heathy and poverty have a negative impact on the growth of the social economy while the environment and social protection \& labor have a positive impact on the growth of the social economy. Regarding the other two econometric models Fixed - Effects Regression and Hausman - Taylor Regression, education, climate change, environment, poverty, social protection \& labor have a positive effect on the growth of the social economy while economic growth and healthy result in a negative impact. Environment and social protection \& labor, in all economic models have resulted in positive impact on the growth of the social economy, in terms of the positive impact on the environment may be because these countries thanks to nature enjoy this environmental level, while in terms of social protection \& labor this positive impact may be as a result of meeting one of the main criteria required by the EU for membership. According to the results, the situation of the social economy in Western Balkan Countries is improving, although at a much slower pace compared to developed European countries such as Spain, France, Sweden, etc., which are hotbeds/ flourishes of social economy.

\section{REFERENCES}

Adams, W.M. (2006) "The Future of Sustainability: Re-thinking Environment and Development in the Twenty-first Century", available at: http://cmsdata.iucn.org/downloads/ iucn_future_of_sustanability.pdf (accessed 28 July 2021).

Ash, A. (2009) The Social Economy: International Perspectives on Economic Solidarity, Zed Books Ltd; First Edition, US.

Chen, J. (2020). "What is poverty?" Available at: https://www.investopedia.com/terms/p/ poverty.asp (accessed 15 October 2021).

European Forum on Social Entrepreneurship (2019) available at: http://efse-bulgaria.eu/en/ efse-subject- social-economy . (accessed 13 August 2021). 
European Parliament, Think Tank (2020) "What future for the social economy"?, available at: https://www.europarl.europa.eu/thinktank/en/document.html?reference=EPRS_BRI(2020)659 336 (accessed 06 August 2021).

Gonzales, P. (2021) "Social economy is a new model for the future of Europe and the World", available at: https://www.socialeconomy.eu.org/2021/04/13/social-economy-as-a-new-modelfor-the-future-of-europe-and-the-world/ (accessed 15 June 2021).

Hall, P., Smith, J., Kay, A., Downing, R., MacPherson, I. and McKitrick, A. (2011) "Introduction: Learning from the Social Economy Community-University Research Partnerships", in Hall, P.V. and MacPherson, I. (Eds) Community-university research partnerships: reflections on the Canadian social economy experience, University of Victoria, Canada. pp. 1-26.

Matković, G. (2019) "The welfare state in Western Balkan countries: challenges and options", available at: http://idn.org.rs/ojs3/stanovnistvo/index.php/STNV/article/download/344/326 (accessed 10 October 2021).

Morley, J. (2016) "Elite networks and the rise of social impact reporting in the UK social sector", available at http://dx.doi.org/10.2139/ssrn.2736167 (accessed 31 July 2021).

OECD (2021) "Environment", available at: https://www.oecd.org/environment/ (accessed 15 October 2021).

OECD/EU (2017) “The Missing Entrepreneurs 2017: Policies for Inclusive Entrepreneurship”, available at: https://doi.org/10.1787/9789264283602-en (accessed 02 August 2021).

Radivojević, V., Krstić, B. and Stanišić, T. (2018) "Environmental sustainability: implications and limitations in WESTERN Balkan countries", available at: http://www.ekonomika.org.rs/ esd/PDF/ekonomika/2018/clanci18-1/3.pdf (accessed 13 October 2021).

Sengupta, U. (2016) "The Future of Social Economy Leadership and Organizational Composition in Canada: Demand from Demographics, and Difference through Diversity”, Revue Interventions économiques, Papers in Political Economy, Vol. 54.

Social Economy Europe (2019) Annual Report Together we stand for the economic and social recovery of Europe, available at https://www.socialeconomy.eu.org/wp-content/uploads/ 2020/06/SEE ANNUAL_REPORT 2019 DIGITAL.pdf (accessed 12 October 2021).

Thomas, R.M. (2021) "Education", available at: https://www.britannica.com/topic/ education/Indian-influences-on-Asia (accessed 12 October 2021).

United Nations (1997) Glossary of Environment Statistics, Studies in Methods, Series F, No. 67, United Nations, New York.

United Nations (2019) Economic and Social Council Report of the Secretary-General, Special edition: progress towards the Sustainable Development Goals, available at: https://undocs.org/E/2019/68 (accessed 12 July 2021).

United Nations (2021) "What is climate change", available at: https://www.un.org/en/climate change/what-is-climate-change (accessed 15 October 2021).

World Bank (2021) "The World Bank in Social Protection", available at: https://www.worldbank.org/en/topic/socialprotection/overview\#1 (accessed 15 October 2021)

World Bank database (2021), available at: https://data.worldbank.org/indicator. 